\title{
Antimicrobial susceptibility of Clostridium difficile isolated in Thailand
}

\author{
Papanin Putsathit ${ }^{1}$, Monthira Maneerattanaporn ${ }^{2}$, Pipat Piewngam³ ${ }^{3}$, Daniel R. Knight ${ }^{1}$, Pattarachai Kiratisin ${ }^{3}$ \\ and Thomas V. Riley ${ }^{1,4^{*}}$
}

\begin{abstract}
Background: Exposure to antimicrobials is the major risk factor associated with Clostridium difficile infection (CDI). Paradoxically, treatment of CDI with antimicrobials remains the preferred option. To date, only three studies have investigated the antimicrobial susceptibility of C. difficile from Thailand, two of which were published in the 1990s. This study aimed to investigate the contemporary antibiotic susceptibility of $C$. difficile isolated from patients in Thailand.

Methods: A collection of 105 C. difficile isolated from inpatients admitted at Siriraj Hospital in Bangkok in 2015 was tested for their susceptibility to nine antimicrobials via an agar incorporation method.

Results: All isolates were susceptible to vancomycin, metronidazole, amoxicillin/clavulanate and meropenem. Resistance to clindamycin, erythromycin and moxifloxacin was observed in $73.3 \%, 35.2 \%$ and $21.0 \%$ of the isolates, respectively. The in vitro activity of fidaxomicin $\left(\mathrm{MIC}_{50} / \mathrm{MIC}_{90} 0.06 / 0.25 \mathrm{mg} / \mathrm{L}\right.$ ) was superior to first-line therapies vancomycin $\left(\mathrm{MIC}_{50} / \mathrm{MIC}_{90}\right.$ $1 / 2 \mathrm{mg} / \mathrm{L}$ ) and metronidazole ( $\mathrm{MIC}_{50} / \mathrm{MIC}_{90} 0.25 / 0.25 \mathrm{mg} / \mathrm{L}$ ). Rifaximin exhibited potent activity against $85.7 \%$ of the isolates (MIC $\leq 0.03 \mathrm{mg} / \mathrm{L})$, and its $\mathrm{MIC}_{50}(0.015 \mathrm{mg} / \mathrm{L})$ was the lowest among all antimicrobials tested. The prevalence of multi-drug resistant $C$. difficile, defined by resistance to $\geq 3$ antimicrobials, was $21.9 \%(23 / 105)$.

Conclusions: A high level of resistance against multiple classes of antimicrobial was observed, emphasising the need for enhanced antimicrobial stewardship and educational programmes to effectively disseminate information regarding $C$. difficile awareness and appropriate use of antimicrobials to healthcare workers and the general public.
\end{abstract}

Keywords: Clostridium difficile, Thailand, Antimicrobial susceptibility

\section{Background}

Antimicrobial exposure is the major risk factor for Clostridium difficile infection (CDI) [1]. In Thailand, many antimicrobials are traded as over-the-counter drugs. When coupled with a general lack of knowledge regarding the appropriate use of antimicrobials in the community, misuse is inevitable [2]. In 2007, an Antimicrobial Smart Use programme was introduced in Thailand by the World Health Organisation (WHO) to promote the rational use of antimicrobials in patients with upper respiratory tract infections, simple wounds and acute diarrhoea. The programme aimed to produce a sustainable behavioural change in prescribing practices. The WHO

\footnotetext{
* Correspondence: thomas.riley@uwa.edu.au

'Microbiology \& Immunology, School of Pathology \& Laboratory Medicine,

The University of Western Australia, Crawley, WA 6008, Australia

${ }^{4}$ Department of Microbiology, PathWest Laboratory Medicine WA, Queen

Elizabeth II Medical Centre, Nedlands, WA 6009, Australia

Full list of author information is available at the end of the article
}

reported a successful pilot intervention and emphasised the importance of collaborative effort and commitment from healthcare practitioners and policy makers in scaling up the programme [2].

Paradoxically, treatment of CDI with antimicrobials remains the preferred option, with vancomycin and metronidazole as first-line therapy. Current knowledge regarding the antimicrobial susceptibility of Thai $C$. difficile isolates is limited to two studies published in the 1990s, and one published in 2015. Among 28 C. difficile investigated in 1994, Kusom et al. reported a high level of resistance $(\geq 50 \%)$ against cefazolin, cefoperazone, tetracycline, erythromycin, clindamycin, ampicillin, bacitracin and cefoxitin. All but one of the test isolates were resistant to $\geq 3$ antimicrobials [3]. In 1996, Wongwanich et al. investigated $38 \mathrm{C}$. difficile isolates using E-strips and reported the $\mathrm{MIC}_{50} / \mathrm{MIC}_{90}$ for teicoplanin, metronidazole, vancomycin and clindamycin to be $0.38 / 0.5$, 
$0.38 / 0.5,1 / 2$ and $2 / \geq 256 \mathrm{mg} / \mathrm{L}$, respectively [4]. More recently, Ngamskulrungroj et al. also used E-strips to investigate 53 toxigenic $C$. difficile and reported the majority (98.2-100\%) to be susceptible to metronidazole, vancomycin, tigecycline and daptomycin. High MICs (>32 $\mathrm{mg} / \mathrm{L}$ ) were observed in $100 \%$ and $43.4 \%$ of the strains tested against ciprofloxacin and moxifloxacin, respectively. The $\mathrm{MIC}_{90}$ of linezolid was $0.5 \mathrm{mg} / \mathrm{L} \mathrm{[5]}$.

We recently investigated the epidemiology of CDI at Siriraj Hospital in Bangkok [6]. From 422 stool specimens, 100 (23.7\%) grew C. difficile yielding 105 isolates. Interestingly, the majority of the strains $(62.9 \%)$ did not contain genes encoding the major virulence factors toxin $\mathrm{A}$ or toxin $\mathrm{B}(\mathrm{A}-\mathrm{B}-)$, while $25.7 \%$ were $\mathrm{A}+\mathrm{B}+$ and $11.4 \%$ were $\mathrm{A}-\mathrm{B}+$. In contrast to much of the rest of the world, none of the isolates carried binary toxin genes (CDT-) [6]. The implications of a high prevalence of nontoxigenic strains are unknown. It is possible that nontoxigenic $C$. difficile could play a protective role against CDI in Thailand [7], or there may be other undetermined virulence factors in these lineages. Indeed, in the previously mentioned study [6] CDI cases exhibited lower morbidity and mortality rates compared to those seen in North America and Europe (Putsathit P. et al., unpublished data). Of concern is the fact that toxigenic strains are capable of converting toxin null strains to toxin producers via horizontal transfer of the pathogenicity locus [8] and that transfer of mobile genetic elements harbouring antimicrobial resistance (AMR) genes has been demonstrated in vitro [9]. Co-colonisation of toxigenic and non-toxigenic strains was demonstrated among Thai patients, indicating the possible risk of such conversion [6].

In the absence of contemporary data and continual injudicious use of antimicrobials in this region $[2,10]$, we investigated the antimicrobial susceptibility of these recently isolated strains of $C$. difficile in Thailand, including assessing the potential risk for AMR transfer from non-toxigenic strains.

\section{Methods}

\section{Collection, isolation and characterisation of C. difficile}

The $105 \mathrm{C}$. difficile strains isolated previously [6] belonged to 38 distinct PCR ribotypes (RTs), $55.2 \%$ (58/ 105) of which were assigned to internationally recognised RTs: $005(n=1), 009(n=6), 010(n=12), 014$ / 020 group $(n=17), 017(n=12), 039(n=9)$ and 103 $(n=1)$. The remaining $44.8 \%(47 / 105)$ of the isolates did not match any reference strains and were designated with an internal nomenclature prefixed QX [6].

\section{Minimum inhibitory concentration (MIC) determination} In vitro susceptibility for fidaxomicin, vancomycin, metronidazole, rifaximin, clindamycin, erythromycin, amoxicillin/clavulanate, moxifloxacin and meropenem was performed by agar incorporation method. Testing and clinical breakpoint determination followed the recommended guidelines of Clinical and Laboratory Standards Institute (CLSI) and European Committee on Antimicrobial Susceptibility Testing (EUCAST) as previously described [11].

\section{Results}

Summary MIC data for nine antimicrobials against $C$. difficile isolates are shown in Table 1 . All isolates were susceptible to vancomycin, metronidazole, amoxicillin/ clavulanate, and meropenem. The in vitro activity of fidaxomicin $\left(\mathrm{MIC}_{50} / \mathrm{MIC}_{90} 0.06 / 0.25 \mathrm{mg} / \mathrm{L}\right)$ was superior to vancomycin $\left(\mathrm{MIC}_{50} / \mathrm{MIC}_{90} 1 / 2 \mathrm{mg} / \mathrm{L}\right)$ and metronidazole $\left(\mathrm{MIC}_{50} / \mathrm{MIC}_{90} 0.25 / 0.25 \mathrm{mg} / \mathrm{L}\right)$. Compared to fidaxomicin, vancomycin and metronidazole, rifaximin exhibited a greater MIC range $(0.008->16 \mathrm{mg} / \mathrm{L})$. The MIC of rifaximin was $\leq 0.03 \mathrm{mg} / \mathrm{L}$ against the majority of the isolates (85.7\%; 90/105) and $\geq 16 \mathrm{mg} / \mathrm{L}$ for the remainder (14.3\%; $15 / 105)$. The $\mathrm{MIC}_{50}$ of rifaximin $(0.015 \mathrm{mg} / \mathrm{L})$ was the lowest of all antimicrobials tested. Nearly $3 / 4$ (73.3\%; 77/ 105 ) of the isolates were resistant to clindamycin, while less resistance to erythromycin $(35.2 \%$; $37 / 105)$ and moxifloxacin $(21.0 \% ; 22 / 105)$ was observed. The prevalence of multi-drug resistance (MDR), as defined by resistance to $\geq 3$ antimicrobials tested, was $21.9 \%(23 / 105)$. This included RTs $017(n=8), 039(n=6)$, QX002 $(n=3), 010$ $(n=2)$, QX190 $(n=2), 009(n=1)$ and QX516 $(n=1)$. Except for RT 017, all of the MDR isolates were nontoxigenic (A-B-CDT-).

Summary MIC and susceptibility data for the nine antimicrobials against $C$. difficile by toxin gene profiles are shown in Table 2 . The $\mathrm{MIC}_{50} / \mathrm{MIC}_{90}$ values of rifaximin against non-toxigenic and $\mathrm{A}+\mathrm{B}+$ isolates were identical $(0.015 / 0.03 \mathrm{mg} / \mathrm{L})$ and lower than those of $\mathrm{A}-\mathrm{B}+$ isolates (>16/>16 mg/L), all of which were RT 017. Similar trends for clindamycin, erythromycin and moxifloxacin were observed where MICs for $\mathrm{A}-\mathrm{B}+$ isolates were higher than those of non-toxigenic and $\mathrm{A}+\mathrm{B}+$ isolates (Table 2). Comparable levels of resistance to clindamycin were observed for non-toxigenic (77.3\%), $\mathrm{A}+\mathrm{B}+(66.7 \%)$ and $\mathrm{A}-\mathrm{B}+$ $(66.7 \%)$ isolates. Compared to non-toxigenic isolates, relatively higher proportions of $\mathrm{A}-\mathrm{B}+$ isolates were resistant to erythromycin $(40.9 \%$ vs. $83.3 \%)$ and moxifloxacin (18.2\% vs. $83.3 \%)$. No erythromycin and moxifloxacin resistance was observed in $\mathrm{A}+\mathrm{B}+$ isolates.

\section{Discussion}

To investigate current trends in the antimicrobial susceptibility of Thai $C$. difficile, 105 recent isolates were tested against nine antimicrobials. Reduced susceptibility to metronidazole ( $\mathrm{MIC}>2 \mathrm{mg} / \mathrm{L}$ ) was not recorded, and the highest $\mathrm{MIC} / \mathrm{MIC}_{50} / \mathrm{MIC}_{90}$ values $(0.5 / 0.25 /$ 
Table 1 Summary MIC data for nine antimicrobials against 105 Thai C. difficile isolates

\begin{tabular}{|c|c|c|c|c|c|c|c|c|c|c|c|c|}
\hline \multirow[t]{2}{*}{ Antimicrobial $^{\mathrm{a}}$} & \multirow{2}{*}{$\begin{array}{c}\text { MIC range } \\
(\mathrm{mg} / \mathrm{L})\end{array}$} & \multirow{2}{*}{$\begin{array}{l}\mathrm{MIC}_{50} \\
(\mathrm{mg} / \mathrm{L})\end{array}$} & \multirow{2}{*}{$\begin{array}{l}\mathrm{MIC}_{90} \\
(\mathrm{mg} / \mathrm{L})\end{array}$} & \multicolumn{3}{|c|}{ Clinical breakpoints [11] } & \multicolumn{2}{|c|}{ Susceptible } & \multicolumn{2}{|c|}{ Intermediate } & \multicolumn{2}{|c|}{ Resistant } \\
\hline & & & & $S$ & 1 & $\mathrm{R}$ & $\mathrm{N}$ & $\%$ & $\mathrm{~N}$ & $\%$ & $\mathrm{~N}$ & $\%$ \\
\hline FDX & $0.004-0.25$ & 0.06 & 0.25 & - & - & - & - & - & - & - & - & - \\
\hline VAN & $0.06-2$ & 1 & 2 & $\leq 2$ & - & $>2$ & 105 & 100.0 & 0 & 0.0 & 0 & 0.0 \\
\hline MTZ & $0.015-0.5$ & 0.25 & 0.25 & $\leq 2$ & - & $>2$ & 105 & 100.0 & 0 & 0.0 & 0 & 0.0 \\
\hline RFX & $0.008->16$ & 0.015 & $>16$ & - & - & - & - & - & - & - & - & - \\
\hline CLI & $0.015->32$ & 8 & $>32$ & $\leq 2$ & 4 & $\geq 8$ & 17 & 16.2 & 11 & 10.5 & 77 & 73.3 \\
\hline ERY & $0.12->256$ & 2 & $>256$ & - & - & $>8$ & - & - & - & - & 37 & 35.2 \\
\hline AMC & $0.03-2$ & 0.5 & 1 & $\leq 4$ & 8 & $\geq 16$ & 105 & 100.0 & 0 & 0.0 & 0 & 0.0 \\
\hline MXF & $0.12-32$ & 2 & 16 & $\leq 2$ & 4 & $\geq 8$ & 82 & 78.1 & 1 & 1.0 & 22 & 21.0 \\
\hline MEM & $0.25-4$ & 2 & 4 & $\leq 4$ & 8 & $\geq 16$ & 105 & 100.0 & 0 & 0.0 & 0 & 0.0 \\
\hline
\end{tabular}

${ }^{a} F D X$ fidaxomicin, VAN vancomycin, MTZ metronidazole, $R F X$ rifaximin, CLI clindamycin, ERY erythromycin, $A M C$ amoxicillin/clavulanate, $M X F$ moxifloxacin, MEM meropenem

$0.25 \mathrm{mg} / \mathrm{L}$, respectively) were lower than those previously reported for Thailand [4]. The lack of resistance against metronidazole is consistent with studies conducted in Australia (MIC range $0.12-1 \mathrm{mg} / \mathrm{L} ; n=440$ [11]) and North America [12], although reduced susceptibility was documented in other North American and European studies [13]. A recent study from Taiwan also reported reduced susceptibility to metronidazole (MIC range of $\leq 0.03-4 \mathrm{mg} / \mathrm{L}$ ), however, growth of $90 \%$ of isolates $(n=403)$ was inhibited at $0.5 \mathrm{mg} / \mathrm{L}$ [14]. Metronidazole MICs of $\geq 4 \mathrm{mg} / \mathrm{L}$ were also observed in $5.3 \%(7 / 131)$ of $C$. difficile isolated in Korea [15].

The $\mathrm{MIC}_{50} / \mathrm{MIC}_{90}$ for vancomycin $(1 / 2 \mathrm{mg} / \mathrm{L})$ were identical to those reported in Thailand by Wongwanich et al., however, according to the epidemiological cut-off (ECOFF) value for vancomycin $(>2 \mathrm{mg} / \mathrm{L})$, their $\mathrm{MIC}$ range $(0.5-3 \mathrm{mg} / \mathrm{L})$ suggests reduced susceptibility [4]. A study conducted in North America reported a decrease in vancomycin susceptibility (MICs of $4 \mathrm{mg} / \mathrm{L}$ ) in $13.2 \%(40 / 302)$ of isolates, including 39.1\% (34/87) of RT 027 strains. None of the isolates carried vanA or $\operatorname{van} B$ genes [12]. Reduced susceptibility (MIC $4 \mathrm{mg} / \mathrm{L}$ ) and resistance (MIC $>8 \mathrm{mg} / \mathrm{L}$ ) to vancomycin was also observed in $2.3 \%$ and $0.9 \%$ of the European isolates $(n=918)$, respectively [16]. Vancomycin MICs of $4 \mathrm{mg} /$ $\mathrm{L}$ were also reported in North America and Europe [13], Taiwan (2/403) [14] and Korea (4/131) [15]. With the appearance of $C$. difficile with reduced vancomycin susceptibility, the 'vancomycin MIC creep' observed among methicillin-resistant Staphylococcus aureus and the global dissemination of vancomycin resistant enterococci [17], appropriate and controlled use of this antimicrobial is increasingly important. However, with regards to CDI, the significance of such increases is doubtful given the high faecal levels of vancomycin achieved with the standard treatment regime $(125 \mathrm{mg}$ orally four times daily) [13].

In the current study, the in vitro activity of fidaxomicin was superior to vancomycin and metronidazole. Using the ECOFF value recommended by the European Medicines Agency (MIC of $>1 \mathrm{mg} / \mathrm{L}$ ) [18], no resistance was observed. The lack of resistance is consistent with

Table 2 Summary MIC data for nine antimicrobials against Thai C. difficile isolates by toxin gene profile

\begin{tabular}{|c|c|c|c|c|c|c|c|c|}
\hline \multirow[t]{2}{*}{ Antimicrobial $^{a}$} & \multicolumn{2}{|c|}{ Toxigenic isolates $(n=39)$} & \multicolumn{2}{|c|}{ A-B- isolates $(n=66)$} & \multicolumn{2}{|c|}{ A+B+ isolates $(n=27)$} & \multicolumn{2}{|c|}{ A-B+ isolates $(n=12)$} \\
\hline & MIC Range & $\mathrm{MIC}_{50} / \mathrm{MIC}_{90}$ & MIC Range & $\mathrm{MIC}_{50} / \mathrm{MIC}_{90}$ & MIC Range & $\mathrm{MIC}_{50} / \mathrm{MIC}_{90}$ & MIC Range & $\mathrm{MIC}_{50} / \mathrm{MIC}_{90}$ \\
\hline FDX & $0.008-0.25$ & $0.06 / 0.25$ & $0.004-0.25$ & $0.06 / 0.25$ & $0.015-0.25$ & $0.12 / 0.25$ & $0.008-0.06$ & $0.03 / 0.06$ \\
\hline VAN & $0.25-2$ & $1 / 2$ & $0.06-2$ & $1 / 1$ & $0.25-2$ & $1 / 2$ & $0.5-2$ & $1 / 1$ \\
\hline MTZ & $0.015-0.25$ & $0.25 / 0.25$ & $0.015-0.5$ & $0.25 / 0.5$ & $0.015-0.25$ & $0.25 / 0.25$ & $0.015-0.25$ & $0.12 / 0.25$ \\
\hline RFX & $0.015->16$ & $0.03 />16$ & $0.008->16$ & $0.015 / 0.03$ & $0.015-0.03$ & $0.015 / 0.03$ & $0.015->16$ & $>16 />16$ \\
\hline CLI & $0.015->32$ & $8 />32$ & $0.03->32$ & $8 />32$ & $0.015-16$ & $8 / 16$ & $0.015->32$ & $>32 />32$ \\
\hline ERY & $0.5->256$ & $2 />256$ & $0.12->256$ & $2 />256$ & $0.5-2$ & $2 / 2$ & $1->256$ & $>256 />256$ \\
\hline AMC & $0.03-1$ & $0.5 / 1$ & $0.03-2$ & $0.5 / 1$ & $0.03-1$ & $0.5 / 1$ & $0.03-1$ & $0.5 / 1$ \\
\hline MXF & $0.12->32$ & $2 / 32$ & $0.12->32$ & $2 / 16$ & $0.12-4$ & $2 / 2$ & $0.25-32$ & $16 / 32$ \\
\hline MEM & $0.25-4$ & $2 / 4$ & $0.25-4$ & $2 / 4$ & $0.5-4$ & $2 / 4$ & $0.25-4$ & $4 / 4$ \\
\hline
\end{tabular}

${ }^{a} F D X$ fidaxomicin, VAN vancomycin, MTZ metronidazole, RFX rifaximin, $C L /$ clindamycin, ERY erythromycin, $A M C$ amoxicillin/clavulanate, $M X F$ moxifloxacin, $M E M$ meropenem. All values are shown in $\mathrm{mg} / \mathrm{L}$ 
previous studies conducted in Europe $\left(\mathrm{MIC}_{50} / \mathrm{MIC}_{90}\right.$ $0.06 / 0.25 \mathrm{mg} / \mathrm{L} ; n=918$ ) [16], North America and Europe $\left(\mathrm{MIC}_{50} / \mathrm{MIC}_{90} 0.125 / 0.25 \mathrm{mg} / \mathrm{L} ; n=719\right)$ [13], Australia $\left(\mathrm{MIC}_{50} / \mathrm{MIC}_{90} 0.03 / 0.12 \mathrm{mg} / \mathrm{L} ; n=440\right)$ [11] and Taiwan $\left(\mathrm{MIC}_{50} / \mathrm{MIC}_{90} 0.12 / 0.25 \mathrm{mg} / \mathrm{L} ; n=403\right)$ [14]. A disadvantage of using fidaxomicin in developing countries is the high cost although a European study suggested that by providing this agent to a targeted patient population in whom superior outcome has been demonstrated, the cost could be indirectly reduced through the shorter period of hospitalisation [19]. The relevance of this in Asia is unclear.

Rifaximin is still under evaluation for treatment of CDI. Although highly active against the majority of $C$. difficile tested, some strains had high MICs [13, 16]. These observations are consistent with results obtained here, where $85.7 \%$ of the isolates had MICs of $\leq 0.03 \mathrm{mg} /$ L. Isolates reported to have high MICs included RT 027, which harboured a mutation in the gene encoding RNA polymerase $\mathrm{B}\left(\right.$ rpoB) [20]. In our study rifaximin $\mathrm{MIC}_{50} /$ $\mathrm{MIC}_{90}$ values for RT $017(\mathrm{~A}-\mathrm{B}+)$ isolates $(>16 />16 \mathrm{mg} / \mathrm{L})$ were higher than those of non-toxigenic and $\mathrm{A}+\mathrm{B}+$ isolates $(0.015 / 0.03 \mathrm{mg} / \mathrm{L}$ in both groups). This suggests a possible alteration in $r p o B$ and warrants further investigation. Rifaximin resistance was previously defined as an MIC of $\geq 32 \mathrm{mg} / \mathrm{L}$ [20]. The highest concentration of rifaximin investigated in this study was $16 \mathrm{mg} / \mathrm{L}$ and $13.3 \%$ of isolates had MICs of $>16 \mathrm{mg} / \mathrm{L}$, indicating possible resistance.

Fluoroquinolones have been strongly associated with CDI and linked to the large outbreaks in Quebec hospitals [21]. In 2011, a study was conducted in a large tertiary hospital in Bangkok to investigate the antimicrobial prescription patterns for adults with acute diarrhoea. Overall, inappropriate use of antimicrobials was $48.9 \%$, with fluoroquinolones and the third generation cephalosporin ceftriaxone being the top agents prescribed [10]. It is therefore not surprising that resistance to moxifloxacin (MIC $\geq 8 \mathrm{mg} / \mathrm{L}$ ) was observed in $21.0 \%$ of Thai isolates given the rapid rate that resistance to quinolones develops following exposure [22]. In Thailand, fluoroquinolone resistance was particularly pronounced among $\mathrm{A}-\mathrm{B}+$, RT 017 isolates (83.3\%), compared to non-toxigenic $(18.2 \%)$ and $\mathrm{A}+\mathrm{B}+(0.0 \%)$ isolates. High proportions of fluoroquinolone resistance were also observed in Taiwan $(17.9 \% ; n=403)$ [14], North America (35.8\%) [12], South Korea (62.6\%; $n=131)$ [15], and Europe $(40.0 \%$ to moxifloxacin; $n=918$ [16]). In contrast, limited resistance has been observed in Australia (3.4\%; $n=440[11])$, likely due to Australia's strict national guidelines for quinolones use in human and their prohibition of use in production animals [23].

A Korean study reported a correlation between the use of clindamycin and the incidence of CDI [24]. In Asia, C. difficile RT 017 is highly prevalent and is known to harbour the ermB gene [15]. This observation supports the high level of resistance to clindamycin $(73.3 \%)$ and erythromycin (35.2\%) observed among Thai isolates, particularly in RT 017 (66.7\% and 83.3\%, respectively). High proportions of clindamycin resistance (MIC of $\geq 8 \mathrm{mg} / \mathrm{L}$ ) were also observed in Europe (50\%; $n=917$ [16]) and North America (36.8\%) [12]. The ermB gene encodes a 23S rRNA methylase conferring resistance to lincosamides and macrolides and is carried on transposons (e.g. Tn6215, Tn6218, Tn6194 and Tn5398, the latter notably having two copies) [25]. CDI caused by strains carrying Tn6194 was more severe with greater mortality (29\% vs. 3\%) [26]. Tn6194 is the most common ermB-containing element in European clinical isolates [27] and carries genes for recombinases and integrases which enable intraand inter-species (Enterococcus faecalis) transfer [28].

In this study, MDR was prevalent (21.9\%) in both toxigenic and non-toxigenic strains. Of note, $66.7 \%$ of RT 017 strains showed multiple resistance. Similar results were observed among RT 017 strains in a North American study that tested $508 \mathrm{C}$. difficile against six antimicrobials (metronidazole, vancomycin, rifampin, clindamycin, moxifloxacin and tetracycline) [12]. Apart from RT 017, the rest of the MDR strains were non-toxigenic; thus, the previously demonstrated intra-species transfer of the pathogenicity locus [8] and AMR genes [9] suggests that these MDR non-toxigenic strains of $C$. difficile are an important consideration.

\section{Conclusions}

C. difficile in Thailand is characterised by a high level of MDR. This includes resistance to fluoroquinolones which are frequently used to treat acute diarrhoeal disease. Education plays a pivotal role in creating behavioural changes and healthcare professionals should be encouraged to inform their patients about the importance of antibiotic stewardship. Although toxigenic culture is not popular as a standalone diagnostic test, stool culturing should still be performed to enable surveillance of the ever-changing epidemiology of CDI and, in particular, the development of AMR. This study demonstrates that both non-toxigenic $C$. difficile and RT 017 strains can be a significant reservoir of AMR and is yet another reminder of the urgent need for antibiotic stewardship in Asia in general and Thailand specifically.

\footnotetext{
Abbreviations

A+/-: Toxin A gene positive/negative; AMC: Amoxicillin/clavulanate; AMR: Antimicrobial resistance; $B+/-$ : Toxin B gene positive/negative; CDI: Clostridium difficile infection; CDT+/-: Binary toxin gene positive/ negative; CLI: Clindamycin; CLSI: Clinical and Laboratory Standards Institute; ECOFF: Epidemiological cut-off MIC value which distinguish wild-type isolates from those with reduced susceptibility; ERY: Erythromycin; EUCAST: European Committee on Antimicrobial Susceptibility Testing; FDX: Fidaxomicin; MDR: Multi-drug resistance; MEM: Meropenem; mg/L: Milligrams per liter; MIC: Minimum inhibitory concentration; $\mathrm{MIC}_{50}$ : MIC required to inhibit the growth of $50 \%$ of organisms; $\mathrm{MIC}_{90}$ : MIC required to
} 
inhibit the growth of $90 \%$ of organisms; MTZ: Metronidazole; MXF: Moxifloxacin; nm: Nanometer; PCR: Polymerase chain reaction; QX: Internal nomenclature, prefix for novel PCR ribotypes; RFX: Rifaximin; RT: PCR ribotype; VAN: Vancomycin; WHO: World Health Organisation

\section{Acknowledgements}

We thank staff in the Microbiology Department at Siriraj Hospital, Bangkok for their assistance with sample collection. We are grateful to our colleagues at PathWest Media (Mt Claremont, Western Australia, Australia) for preparation of the testing media.

\section{Funding}

This study was supported by internal funding. PPu and DRK are funded by postgraduate awards conferred by The University of Western Australia.

\section{Availability of data and materials}

The datasets used and/or analysed during the current study are available from the corresponding author on request.

\section{Authors' contributions}

PPu participated in the conceptualisation of the study, performed the laboratory work and data analysis, and wrote and edited the manuscript drafts. PPi and MM managed specimen collection. DRK provided critical assistance in laboratory work and data analysis, and participated in critical revision of the manuscript. PK participated in the conceptualisation of the study, managed specimen collection, and participated in critical revision of the manuscript. TVR participated in the conceptualisation of the study, managed specimen collection, oversaw the analysis of data, and provided extensive assistance in critical revision of the manuscript. All authors read and approved the final manuscript.

\section{Competing interests}

The authors declare that they have no competing interests.

\section{Consent for publication}

Not applicable.

\section{Ethics approval and consent to participate}

The work was approved by The University of Western Australia Human Research Ethics Committee (approval no. RA/4/1/7616), and the Institutional Review Board of Siriraj Hospital, Bangkok (approval no. Si 132/2015).

\section{Publisher's Note}

Springer Nature remains neutral with regard to jurisdictional claims in published maps and institutional affiliations.

\section{Author details}

${ }^{1}$ Microbiology \& Immunology, School of Pathology \& Laboratory Medicine, The University of Western Australia, Crawley, WA 6008, Australia. ${ }^{2}$ Department of Medicine, Faculty of Medicine Siriraj Hospital, Mahidol University, Bangkok 10700, Thailand. 3Department of Microbiology, Faculty of Medicine Siriraj Hospital, Mahidol University, Bangkok 10700, Thailand. ${ }^{4}$ Department of Microbiology, PathWest Laboratory Medicine WA, Queen Elizabeth II Medical Centre, Nedlands, WA 6009, Australia.

\section{Received: 16 December 2016 Accepted: 30 May 2017} Published online: 08 June 2017

\section{References}

1. Bignardi GE. Risk factors for Clostridium difficile infection. J Hosp Infect. 1998:40:1-15

2. Sumpradit N, Chongtrakul P, Anuwong K, Pumtong S, Kongsomboon K, Butdeemee $\mathrm{P}$, et al. Antibiotics Smart Use: a workable model for promoting the rational use of medicines in Thailand. Bull World Health Organ. 2012:90:641-944

3. Kusum M, Wongwanich S. Susceptibility of Clostridium difficile to sixteen antimicrobial agents. J Health Sci. 1994;3:255-61.

4. Wongwanich S, Kusum M, Phan-Urai R. Antibacterial activity of teicoplanin against Clostridium difficile. Southeast Asian J Trop Med Public Health. 1996;27:606-9.
5. Ngamskulrungroj $P$, Sanmee $S$, Putsathit P, Piewngam $P$, Elliott B, Riley TV, et al. Molecular epidemiology of Clostridium difficile infection in a large teaching hospital in Thailand. PLoS One. 2015;10:e0134771.

6. Putsathit $P$, Maneerattanaporn $M$, Piewngam $P$, Kiratisin $P$, Riley $T$. Prevalence and molecular epidemiology of Clostridium difficile infection in Thailand. New Microbes New Infect. 2017;15:27-32.

7. Gerding DN, Meyer T, Lee C, Cohen SH, Murthy UK, Poirier A, et al. Administration of spores of nontoxigenic Clostridium difficile strain M3 for prevention of recurrent $C$. difficile infection: a randomized clinical trial. JAMA. 2015;313:1719-27.

8. Brouwer MS, Roberts AP, Hussain H, Williams RJ, Allan E, Mullany P. Horizontal gene transfer converts non-toxigenic Clostridium difficile strains into toxin producers. Nat Commun. 2013;4:2601.

9. Goh S, Hussain H, Chang BJ, Emmett W, Riley TV, Mullany P. Phage C2 mediates transduction of Tn6215, encoding erythromycin resistance, between Clostridium difficile strains. MBio. 2013;4(6):e00840-13.

10. Supcharassaeng S, Suankratay C. Antibiotic prescription for adults with acute diarrhea at King Chulalongkorn Memorial Hospital, Thailand. J Med Assoc Thai. 2011;94:545-50.

11. Knight DR, Giglio S, Huntington PG, Korman TM, Kotsanas D, Moore CV, et al. Surveillance for antimicrobial resistance in Australian isolates of Clostridium difficile, 2013-14. J Antimicrob Chemother. 2015;70:2992-9.

12. Tickler IA, Goering RV, Whitmore JD, Lynn AN, Persing DH, Tenover FC, et al. Strain types and antimicrobial resistance patterns of Clostridium difficile isolates from the United States, 2011 to 2013. Antimicrob Agents Chemother. 2014;58:4214-8.

13. Goldstein EJ, Citron DM, Sears P, Babakhani F, Sambol SP, Gerding DN. Comparative susceptibilities to fidaxomicin (OPT-80) of isolates collected at baseline, recurrence, and failure from patients in two phase III trials of fidaxomicin against Clostridium difficile infection. Antimicrob Agents Chemother. 2011;55:5194-9.

14. Liao CH, Ko WC, Lu JJ, Hsueh PR. Characterizations of clinical isolates of Clostridium difficile by toxin genotypes and by susceptibility to 12 antimicrobial agents, including fidaxomicin (OPT-80) and rifaximin: a multicenter study in Taiwan. Antimicrob Agents Chemother. 2012;56:3943-9.

15. Kim J, Kang JO, Pai H, Choi TY. Association between PCR ribotypes and antimicrobial susceptibility among Clostridium difficile isolates from healthcare-associated infections in South Korea. Int J Antimicrob Agents. 2012:40:24-9.

16. Freeman J, Vernon J, Morris K, Nicholson S, Todhunter S, Longshaw C, et al. Pan-European longitudinal surveillance of antibiotic resistance among prevalent Clostridium difficile ribotypes. Clin Microbiol Infect. 2015;21:248. e9-e16

17. Willems R, Top J, Van Santen M, Robinson DA, Coque TM, Baquero F, et al Global spread of vancomycin-resistant Enterococcus faecium from distinct nosocomial genetic complex. Emerg Infect Dis. 2005;11:821-8.

18. Committee for Medicinal Products for Human Use (CHMP) EMA. Assessment report - Fidaxomicin (Procedure No: EMEA/H/C/2087). 2011.

19. Rubio-Terres C, Cobo Reinoso J, Grau Cerrato S, Mensa Pueyo J, Salavert Lleti $\mathrm{M}$, Toledo A, et al. Economic assessment of fidaxomicin for the treatment of Clostridium difficile infection (CDI) in special populations (patients with cancer, concomitant antibiotic treatment or renal impairment) in Spain. Eur J Clin Microbiol Infect Dis. 2015;34:2213-23.

20. O'Connor JR, Galang MA, Sambol SP, Hecht DW, Vedantam G, Gerding DN, et al. Rifampin and rifaximin resistance in clinical isolates of Clostridium difficile. Antimicrob Agents Chemother. 2008:52:2813-7.

21. Pepin J, Saheb N, Coulombe MA, Alary ME, Corriveau MP, Authier S, et al. Emergence of fluoroquinolones as the predominant risk factor for Clostridium difficile-associated diarrhea: a cohort study during an epidemic in Quebec. Clin Infect Dis. 2005;41:1254-60.

22. Ackermann G, Tang-Feldman YJ, Schaumann R, Henderson JP, Rodloff AC, Silva J, et al. Antecedent use of fluoroquinolones is associated with resistance to moxifloxacin in Clostridium difficile. Clin Microbiol Infect. 2003;9:526-30.

23. Cheng AC, Turnidge J, Collignon P, Looke D, Barton M, Gottlieb T. Control of fluoroquinolone resistance through successful regulation, Australia. Emerg Infect Dis. 2012;18:1453.

24. Kim J, Kang JO, Kim H, Seo MR, Choi TY, Pai H, et al. Epidemiology of Clostridium difficile infections in a tertiary-care hospital in Korea. Clin Microbiol Infect. 2013:19:521-7.

25. Leclercq R. Mechanisms of resistance to macrolides and lincosamides: nature of the resistance elements and their clinical implications. Clin Infect Dis. 2002;34:482-92. 
26. Corver J, Bakker D, Brouwer MS, Harmanus C, Hensgens MP, Roberts AP, et al. Analysis of a Clostridium difficile PCR ribotype 078100 kilobase island reveals the presence of a novel transposon, Tn6164. BMC Microbiol. 2012;12:130.

27. Spigaglia P. Recent advances in the understanding of antibiotic resistance in Clostridium difficile infection. Ther Adv Infect Dis. 2016;3:23-42.

28. Knight DR, Elliott B, Chang BJ, Perkins TT, Riley TV. Diversity and evolution in the genome of Clostridium difficile. Clin Microbiol Rev. 2015;28:721-41.

Submit your next manuscript to BioMed Central and we will help you at every step:

- We accept pre-submission inquiries

- Our selector tool helps you to find the most relevant journal

- We provide round the clock customer support

- Convenient online submission

- Thorough peer review

- Inclusion in PubMed and all major indexing services

- Maximum visibility for your research

Submit your manuscript at www.biomedcentral.com/submit 